\title{
Do medically unexplained symptoms matter? A prospective cohort study of 300 new referrals to neurology outpatient clinics
}

\author{
Alan J Carson, Brigitte Ringbauer, Jon Stone, Lesley McKenzie, Charles Warlow, \\ Michael Sharpe
}

\begin{abstract}
Objectives-To determine (a) the proportion of patients referred to general neurology outpatient clinics whose symptoms are medically unexplained; (b) why they were referred; (c) health status and emotional disorder in this group compared with patients whose symptoms are explained by "organic" neurological disease.

Methods-The prospective cohort study with case note follow up at 6 months was carried out in the regional neurology service in Lothian, Scotland with 300 newly referred outpatients. Neurologists rated the degree to which patients' symptoms were explained by organic disease (organicity), GPs' reasons for referral, health status (SF-36), anxiety, and depressive disorders (PRIME-MD),

Results-Of 300 new patients $11 \%(95 \%$ confidence interval (95\% CI) 7\%-14\%) had symptoms that were rated as "not at all explained" by organic disease, $19 \%(15 \%$ to $23 \%)$ "somewhat explained", $27 \%(22 \%$ to $32 \%$ ) "largely explained", and $43 \%$ (37\% to $49 \%$ ) "completely explained" by organic disease. Reason for referral was not associated with "organicity". Comparison of these groups showed that although physical function was similar, the median number of physical symptoms and pain were greater in patients with lower organicity ratings $(p<0.0005$, $\mathrm{p}<0.0005)$. Depressive and anxiety disorders were more common in patients with symptoms of lower organicity $(70 \%$ of patients in the not at all group had an anxiety or depressive disorder compared with $32 \%$ in the completely explained group $(\mathrm{p}<0.0005)$.

Conclusion-One third of new referrals to general neurology clinics have symptoms that are poorly explained by identifiable organic disease. These patients were disabled and distressed. They deserve more attention.
\end{abstract}

(F Neurol Neurosurg Psychiatry 2000;68:207-210)

Keywords: unexplained symptoms; somatisation; neurology
Patients who present with symptoms that are unexplained by organic disease are common in all medical settings. ${ }^{1-3}$ There is much less information on, and acceptance of, their importance as a clinical problem, however. We conducted a study in a neurological service to determine the prevalence of such patients and their importance as defined by patients' disability and distress.

\section{Methods}

Neurology services in Lothian are provided by eight consultants and their junior staff. All outpatient clinics take general referrals, which are allocated by clerical staff according to available appointments. Clinic templates dictate the number of urgent, semiurgent, and routine appointments available in each clinic. The case mix is very similar to that described for other services. $^{4}$

\section{SAMPLING}

The study was conducted between November 1997 and March 1998 in five of the eight consultant outpatient clinics (CW, RG, CL, CM, $\mathrm{AZ}$, see acknowledgements). Some patients were seen initially by a specialist registrar, but their cases were reviewed by a consultant at the time of initial consultation. Limiting the number of clinics to five allowed one clinic to be studied each weekday. All new patients were included except in one clinic where, because of the large number attending, every alternate new patient was included.

\section{PROCEDURES AND MEASURES}

The ratings of the degree to which the patients' symptoms were considered to be medically explained were obtained from the neurologist. They rated their opinion on a four point Likert scale ("not at all explained", "somewhat explained","largely explained", and "completely explained") immediately after the initial consultation. This is referred to as the organicity rating. Such a system has been shown to be reliable. ${ }^{5} 6$

To determine the validity of these ratings the neurological case notes were reviewed (by AC and JS), in consultation with the treating consultant when necessary, 6 months later after 
Table 1 General practitioners' main reason for referral by neurologists' rating of organicity $(n=300)$

\begin{tabular}{|c|c|c|c|c|c|}
\hline \multirow[b]{2}{*}{ Reason for referral } & \multicolumn{4}{|c|}{$\begin{array}{l}\text { To what extent can the patient's symptoms be explained by } \\
\text { organic disease? }\end{array}$} & \multirow[b]{2}{*}{$n(\%, 95 \% C I)$} \\
\hline & Not at all & Somewhat & Largely & Completely & \\
\hline Neurological diagnosis and treatment & 10 & 30 & 46 & 68 & $154(51 \%, 46 \%-57 \%)$ \\
\hline Patient request & 1 & 7 & 5 & 9 & $22(7 \%, 5 \%-11 \%)$ \\
\hline Reinforce my opinion no disease & 8 & 9 & 4 & 7 & $28(9 \%, 6 \%-13 \%)$ \\
\hline Other ${ }^{\star}$ & 6 & 3 & 11 & 17 & $37(12 \%, 9 \%-16 \%)$ \\
\hline Referred by GP trainee $\dagger$ & 0 & 0 & 1 & 8 & $9(3 \%, 1 \%-6 \%)$ \\
\hline Referred by other consultant $\ddagger$ & 4 & 3 & 6 & 11 & $24(8 \%, 5 \%-12 \%)$ \\
\hline No reply & & & & & $25(8 \%)$ \\
\hline
\end{tabular}

*This was usually to answer a specific question of management, most commonly the use of anti-convulsants during pregnancy or beta- interferon for multiple sclerosis.

†Most GP trainees had left the patient's practice and were therefore unable to endorse a reason for referral. Therefore all GP trainee referrals are listed separately.

$\ddagger$ Similarly "consultant" referrals were often made by senior house officers or registrars who were unavailable to comment on the reason for referral.

further assessment and investigations had been performed. The final diagnosis was recorded and any change in opinion regarding the organicity of the complaint noted.

Before their patients' attendance at the clinic, the general practitioners (GPs) were sent a brief questionnaire asking them to indicate why they had referred the patient by endorsing one of four reasons listed in table 1 .

Patients who gave informed consent for participation were assessed by AC or BR (using the measures below) within 7 days of their neurological consultation. Patients' perception of health status and disability was measured using the medical outcome study scale $(\mathrm{SF}-36){ }^{7}$ This self report scale examines health status in eight domains. It was scored as recommended by their authors. ${ }^{8}$ In all domains of the SF-36 a lower score is indicative of poorer health (worse functioning or increased pain). Patients also completed a check list that inquires about common physical symptoms (see appendix)..$^{910}$ This was to obtain a measure of the number of different physical symptoms they had.

Diagnoses of anxiety and depression disorders (emotional disorders) were made using the primary care evaluation of mental disorders (PRIME-MD), ${ }^{11}$ a brief structured interview producing DSM IV ${ }^{12}$ diagnoses, of established reliability and validity. A sample of 50 of BR's interviews were tape recorded and rerated blind by AC to check interrater reliability. Only one case was categorised as having an emotional disorder by BR and not by AC.

The study was approved by the local research ethics committee

\section{ANALYSIS}

The analysis was undertaken in three stages:

We calculated the prevalence of medically unexplained symptoms (MUS) from the neurologist's organicity rating.

We examined the GP's reason for referral by organicity rating.

We compared the four groups defined by the neurologists' organicity rating for health status, number of physical symptoms, and emotional disorder diagnoses. The non-parametric Kruskal-Wallis test was employed as the data were not normally distributed. Confidence intervals were calculated using non-parametric techniques and appropriate tables. ${ }^{13}$

\section{Results}

Of 364 new patients booked in the designated clinics during the study period 48 did not attend, leaving 316 eligible to participate. Of these, 12 refused, one was too cognitively impaired to be assessed, two patients were lost to assessment, and one found the assessment distressing and withdrew. This left 300 patients, a participation rate of $96 \%$ of attenders and $82 \%$ of referrals.

Of the patients included $174(58 \%)$ were female. The mean age was 43 (range 14 to 88 ) years. Of the 300 patients 33 (11\%) had symptoms which were considered to be not at all explained by organic disease and a further 57 $(19 \%)$ had symptoms only somewhat explained by organic disease. This compared with $81(27 \%)$ who had symptoms largely explained and 129 (43\%) whose symptoms were completely explained by organic disease. At the 6 month case note review, there had been little change in the neurologists' opinion concerning organicity. In four cases expected organic causes were not confirmed by investigation. In a further six cases, where patients had been rated as having largely or completely explained symptoms, unexpected organic causes of disease were found. Thus, although the diagnosis changed the organicity rating did not. There were no cases in which an organic cause emerged for symptoms initially considered not at all or somewhat explained.

The GPs' reasons for referral are shown in table 1 . When the reasons for referral were compared by organicity rating we found that about two thirds $(14,64 \%)$ of the 22 patients who had been referred at their own request had symptoms that were largely or completely explained by organic disease. Of those 28 patients referred to "reinforce my opinion of no neurological disease" 11 (39\%) were considered by the neurologists to have symptoms which were largely or completely explained.

Patients' characteristics are shown in table 2. The groups did not differ substantially or significantly in terms of age or sex. Neither, were there statistically significant differences between them in their general health perception, physical function, or physical role function as measured by the SF-36. Patients whose symptoms had lower organicity ratings did, however, report a significantly greater number of physical symptoms, more bodily pain, and 
Table 2 Associations of the neurologists'organicity rating of patients'symptoms with age, sex, disability, and emotional disorders

\begin{tabular}{|c|c|c|c|c|c|c|}
\hline \multirow[b]{2}{*}{ Variable } & \multicolumn{4}{|c|}{ To what extent can the patient's symptoms be explained by organic disease? } & \multirow[b]{2}{*}{$X^{2}(3 d f)$} & \multirow[b]{2}{*}{$p$ Value } \\
\hline & Not at all & Somewhat & Largely & Completely & & \\
\hline No of patients $(\%, 95 \% \mathrm{CI}))$ & $33(11 \%, 7 \%-14 \%)$ & $57(19 \%, 15 \%-23 \%)$ & $81(27 \%, 22 \%-32 \%)$ & $129(43 \%, 37 \%-49 \%)$ & & \\
\hline Number male $(\%, 95 \%$ CI $))$ & $11(33 \%, 18 \%-52 \%)$ & $22(39 \%, 26 \%-52 \%)$ & $34(42 \%, 31 \%-53 \%)$ & $58(45 \%, 36 \%-54 \%)$ & 1.9 & 0.6 \\
\hline Median age (range) & $40(37-44)$ & $41(37-43)$ & $40(36-44)$ & $43(40-48)$ & 1.9 & 0.6 \\
\hline $\begin{array}{l}\text { Median No of physical symptoms } \\
\text { (range) }\end{array}$ & $6(4-8)$ & $5(4-6)$ & $5(4-6)$ & $3(2-3)$ & 35.3 & $<0.0005$ \\
\hline \multicolumn{7}{|l|}{ Median SF-36 scores ${ }^{\star}$ (range): } \\
\hline General health & $57(52-60)$ & $57(57-60)$ & $57(52-57)$ & $57(55-57)$ & 1.4 & 0.7 \\
\hline Physical functioning & $75(70-90)$ & $85(65-95)$ & $85(70-95)$ & $80(75-85)$ & 0.4 & 0.9 \\
\hline Role functioning: physical & $50(0-100)$ & $50(25-100)$ & $75(50-100)$ & $75(75-100)$ & 2.9 & 0.4 \\
\hline Bodily pain & $51(31-64)$ & $51(40-60)$ & $61(50-70)$ & $74(72-84)$ & 21.1 & $<0.0005$ \\
\hline Social functioning & $62(50-100)$ & $62(50-75)$ & $75(62-100)$ & $88(88-100)$ & 16.3 & 0.001 \\
\hline Vitality & $40(30-45)$ & $45(35-50)$ & $50(40-55)$ & $50(50-60)$ & 16.3 & 0.001 \\
\hline Role functioning: emotional & $100(0-100)$ & $67(0-100)$ & $100(0-100)$ & $100(100-100)$ & 18.4 & $<0.0005$ \\
\hline Mental health & $56(48-68)$ & $60(52-68)$ & $72(64-76)$ & $76(72-80)$ & 21.3 & $<0.0005$ \\
\hline $\begin{array}{l}\text { No ( } \%, 95 \% \mathrm{CI}) \text { with anxiety or } \\
\text { depressive disorder }\end{array}$ & $23(70 \%, 51 \%-84 \%)$ & $37(65 \%, 51 \%-77 \%)$ & $39(48 \%, 37 \%-60 \%)$ & $41(32 \%, 24 \%-40 \%)$ & 26.2 & $<0.0005$ \\
\hline
\end{tabular}

^All SF-36 scores range from 0 to 100 , a lower score equates with poorer health status.

more impaired social functioning. A significantly greater number of patients in the low organicity groups were diagnosed as having anxiety and depressive disorders. This was reflected in their increased impairment on the vitality, emotional role function, and mental health scales of the SF-36.

\section{Discussion}

One third of new general neurology outpatient attenders had symptoms which were either not at all or only somewhat explained by organic disease. A 6 month case note review showed that further assessment and investigation had not disclosed an organic cause of disease in any of these patients. In the few cases in which opinion did change, this was only because expected organic causes of disease were not confirmed by further assessment and investigations. The neurologists' ratings of medically unexplained symptoms were therefore valid, at least in the short term.

In most cases, patients with unexplained symptoms had been referred because they needed neurological diagnosis and possible treatment. Given this, and the finding that 39\% of the patients referred to as "reinforce my opinion of no neurological disease" in fact had definable organic disease, we suggest that specialist opinion has an important part to play in clarifying the clinical situation in these complex patients.

Self reported physical functioning was just as impaired in patients whose symptoms were of lower organicity as in those whose symptoms were associated with identified organic disease. Furthermore, patients with complaints of low organicity reported a greater number of physical symptoms, more pain, and were more likely to have emotional disorders. Symptom clusters of multiple, painful complaints, particularly in depressed or anxious patients, should be regarded as diagnostic pointers towards unexplained symptoms. It should be noted that this is a highly debilitating picture and comments such as "don't worry, there is nothing really wrong here" are likely to be disbelieved or annoy patients, who perceive themselves to be in great suffering. Therefore, clinically it is necessary to give some validation to the reality of the patients' symptoms before starting to explore aetiological models with them.

These findings must be considered in the context of potential methodological shortcomings. Firstly, although the clinics were considered representative of the overall service, and referrals were taken from a common pool, certain specialised clinics, in particular neurovascular and memory clinics, were not represented in the study sample. The sample may therefore not be fully representative of neurology outpatient referrals. This limitation notwithstanding, the very high participation rate of $96 \%$ of patients suggests that this sample is representative of new attenders to the general neurology outpatient clinics. Secondly, there must be some uncertainty about how the threshold for referral, or the view of what constitutes an appropriate referral among local GPs, compares with that of GPs elsewhere.

The finding that $30 \%$ of referred patients had symptoms that were not well explained by organic disease is in agreement with previous reports. Perkin, ${ }^{4}$ in his review of 7836 consecutive new neurological patients whom he had seen personally at Charing Cross Hospital, reported that $26 \%$ of patients received no medical diagnosis and a further $4 \%$ had symptoms of conversion hysteria. Similar findings have been shown in female in-patient neurological populations by Creed et $a l^{14}$ The important new findings from our study are that this group of patients are disabled by their symptoms and have very high rates of emotional disorder.

This frequency of medically unexplained symptoms does not seem to be unique to general neurology. Two retrospective case note reviews indicate the frequency in other settings: in United States ambulatory care Kroenke and Mangelsdorff ${ }^{15}$ found that only $16 \%$ of physical complaints were explained by organic disease. In United Kingdom outpatient care, Hamilton et $a \beta^{\beta}$ reported rates of $53 \%, 42 \%$, and $32 \%$ in gastroenterology, neurology, and cardiology, respectively for the percentage of patients whose symptoms remained medically unexplained after assessment.

In our study, the patients with anxiety and depressive disorders were overrepresented among those whose symptoms were considered 
less organic. However, it should be noted both that emotional disorders were also common in patients with identifiable neurological disease and that many of the patients with unexplained symptoms did not have definite evidence of emotional disorder.

Given the substantial number of patients with symptoms largely unexplained by identifiable organic disease; disability at least as high as in those patients with a more definite explanation for their symptoms, and a greater likelihood of emotional disorder, we suggest that this group of patients has been neglected. Research into the treatment of symptoms not clearly explained by organic disease should therefore, in our opinion, enjoy a higher priority than it currently does.

We thank Dr Grant, Dr Lueck, Dr Mumford, Dr Zeman, their junior staff, the nursing staff, and the medical records officers of the Department of Clinical Neurology, Western General Hospital, Edinburgh. We are particularly grateful to the general practitioners of south east Scotland for their high level of participation, to Mr Signorini (DCN,WGH) for his statistical advice, and to Professor R Mayou and Professor F Creed for helpful comments on earlier drafts of this manuscript. The study was funded by the University of Edinburgh.

1 Gureje O, Simon GE, Ustun TB, et al. Somatization in cross-cultural perspective: a World Health Organization study in primary care. Am f Psychiatry 1997;154:989-95.

study in primary care. Am f Psychiatry 1997;154:989-95.
2 Kirk C, Saunders M. Primary psychiatric illness in a neurological out-patient department in north east England. Acta logical out-patient department in 1 .

3 Hamilton J, Campos R, Creed F. Anxiety, depression and the management of medically unexplained symptoms in medical clinics. F R Coll Physicians Lond 1996;30:18-20.

4 Perkin GD. An analysis of 7836 sucessive new outpatient referrals. $\mathcal{F}$ Neurol Neurosurg Psychiatry 1989;52:447-8.

5 Speckens AEM, Van Hemert AM, Bolk JH, et al. Unexplained physical symptoms: outcome, utilization of medical care and associated factors. Psychol Med 1996;26: 745-52.

6 Crimlisk HL, Bhatia K, Cope H, et al. Slater revisited: 6 year follow up study of patients with medically unexplained motor symptoms. BMF 1998;316:582-6.

\section{Appendix}

Rating scale for the number of physical symptoms suffered by subject During the PAST MONTH, have you been bothered A LOT by

\begin{tabular}{lll}
\hline & Yes & No \\
1. Stomach pain & {[]} & {[]} \\
2. Back pain & {[]} & {[]} \\
3. Pain in your arms, legs, or joints (knees, hips, etc) & {[]} & {[]} \\
4. Menstrual pain or problems & {[]} & {[]} \\
5. Pain or problems during sexual intercourse & {[]} & {[]} \\
6. Headaches & {[]} & {[]} \\
7. Chest pain & {[]} & {[]} \\
8. Dizziness & {[]} & {[]} \\
9. Fainting spells & {[]} & {[]} \\
10. Feeling your heart pound or race & {[]} & {[]} \\
11. Shortness of breath & {[]} & {[]} \\
12. Constipation, loose bowels, or diarrhoea & {[]} & {[]} \\
13. Nausea, gas, or indigestion & {[]} & {[]} \\
14. Feeling tired or having low energy & {[]} & {[]} \\
15. Trouble sleeping & {[]} & {[]}
\end{tabular}

7 Ware JE, Sherbourne CD. The MOS 36-item short-form health survey (SF-36). Conceptual framework and Item selection. Med Care 1992;30:473-83.

8 Medical Outcomes Trust. How to score the SF-36 health survey. PO Box 1917, Boston, MA 02205, USA: Medical Outcomes Trust, 1994.

9 Schappert SM. National ambulatory medical care survey. Vital Health Stat 13 1989;110:2-11

10 Kroenke K, Arrington ME, Mangelsdorff AD. The prevalence of symptoms in medical outpatients and the adequacy of therapy. Arch Intern Med 1990;150:1685-9.

11 Spitzer RL, Williams JB, Kroenke K, et al. Utility of a new procedure for diagnosing mental disorders in primary care. The PRIME-MD 1000 study. FAMA 1994;272:1749-56.

12 American Psychiatric Association. Diagnostic and statistical manual of mental disorders. 4th ed. Washington, DC: American Psychiatric Association, 1994.

13 Gardner MJ, Altman DG. Statistics with confidence: confidence intervals and statistical guidelines. Belfast: The Universities Press, 1989

14 Creed F, Firth D, Timol M, et al. Somatization and illness behaviour in a neurology ward. $\mathcal{F}$ Psychosom Res 1990;34: 427-37.

15 Kroenke K, Mangelsdorff AD. Common symptoms in ambulatory care: incidence, evaluation, therapy and outcome. Am F Med 1989;86:262-6. 